\title{
Elaboração e aplicação de um jogo didático para o ensino de ligações químicas: uma intervenção da residência pedagógica.
}

Development and application of a didactic game for teaching chemical bonds: an intervention of the pedagogical residence.

Elaboración y aplicación de un juego didáctico para la enseñanza del enlace químico: una intervención de residência pedagógica.

\section{Samuel Nepomuceno Ferreira ${ }^{* 1}$, Marcos Wilson Vicente de Assis ${ }^{2}$, Daniel Augusto} Barra de Oliveira $^{2}$, Edenilson dos Santos Niculau ${ }^{2}$

${ }^{1}$ Instituto Federal de Educação, Ciência e Tecnologia do Tocantins-Campus Araguaína, Araguaína, Brasil.

${ }^{2}$ Curso de Licenciatura em Química, Universidade Federal do Tocantins-Campus Cimba, Araguaína, Brasil.

*Correspondência: Instituto Federal do Tocantins-Campus Araguaína, Av. Amazonas, esquina com Av.

Paraguai, Quadra 56, Lote 01, Araguaína, Tocantins, Brasil. CEP:77.824-838. e-mail

samuel.ferreira@ifto.edu.br.

Artigo recebido em 28/02/2020 aprovado em 27/05/2020 publicado em 03/07/2020.

\section{INTRODUÇÃO}

Tendo em vista as constantes modificações do mundo globalizado e a necessidade de se repensar os processos educativos escolares, em especial na educação básica, novas tendências educacionais nos levam à reflexão acerca de possibilidades da implementação de ações mais dinâmicas no processo de ensino e aprendizagem.

Alguns autores, dentre eles Silva et al. (2017), perceberam que a proposta de um jogo didático para o ensino de Química, por se apresentar como um momento lúdico, tem a possibilidade de associar o aprendizado dos conteúdos abordados nas aulas com atitudes e valores importantes do processo de escolarização, como a interação e a cooperação coletiva. Além dessas considerações, segundo estes autores, há uma predisposição dos estudantes para a utilização de jogos didáticos em contraponto ao processo de aprendizagem puramente tradicionalista.

Ao se pensar sobre a prática docente, Zanon et al. (2008) nos desperta sobre a necessidade da presença mais frequente dos jogos didáticos como práticas pedagógicas no ensino, visto que são motivadoras e promovem a aprendizagem juntamente com habilidades comportamentais.

O objetivo central deste artigo se sustenta na descrição de potencialidades e desafios da proposição de um jogo didático para a validação da aprendizagem de conceitos para ligações químicas para o ensino médio aplicada no contexto da etapa de intervenção pedagógica do Programa de Residência Pedagógica da UFT, campus Araguaína.

\section{MATERIAIS E MÉTODOS}

O Programa de Residência Pedagógica apresenta em uma de suas etapas de execução a imersão na escola-campo, momento em que os residentes (bolsistas ou voluntários) se tornam regentes da(s) turma(s) envolvida(s) no processo.

Como proposta desta imersão, foi elaborado e aplicado um jogo didático pelos residentes bolsistas do programa e orientado pelo professor 
regente de uma turma com 25 alunos de $1^{\circ}$ (primeiro) ano do curso técnico de informática integrado ao ensino médio do Instituto Federal do Tocantins (IFTO), campus de Araguaína.

O jogo foi estruturado para transcorrer ao longo de 1 (uma) aula de 50 minutos para consolidação da aprendizagem dos conceitos de ligações químicas, aprendizagem esta que envolveu diálogos sobre conceitos em sala de aula e atividade prática experimental. Portanto, o objetivo principal do jogo foi consolidar o aprendizado iniciado em sala e desenvolvido ao longo da sequência por meio de atividades experimentais e/ou expositivas.

Após escutar o som de um apito, cada participante buscava formar compostos químicos com outro(s) participante(s), precisando assim verificar se as duas (ou mais) cartas juntas poderiam formar um composto e assim, descrever as características das ligações.

Para a aplicação do jogo é necessário que se tenham as cartas (confeccionadas em papel A4 e fixadas em papelão), um relógio (cronômetro) e um apito. Para a confecção das cartas do jogo os seguintes materiais foram empregados, conforme a figura 1 e exemplificadas na figura 2 :

1-Caixas de papelão (de preferência sem dobras); 2Tesoura ou estilete; 3-Cola Branca; 4-Papel A4 impresso.

FIGURA 1- Materiais utilizados para confecção das cartas do jogo.

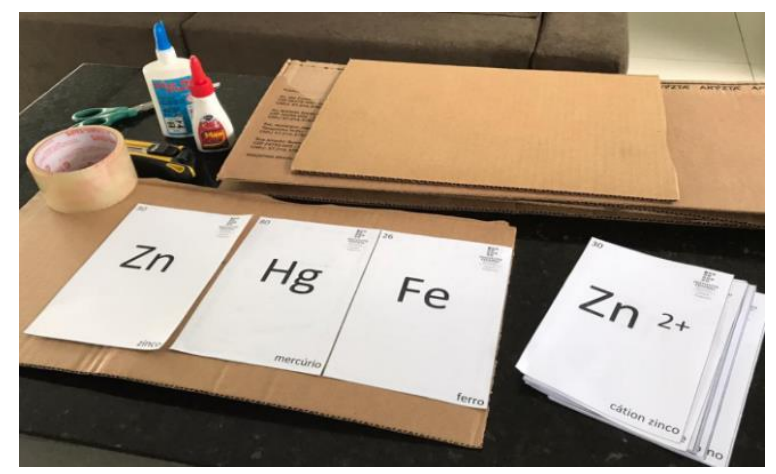

Fonte: Elaborada pelo autor, 2019.
FIGURA 2-Modelo das cartas utilizadas no jogo.

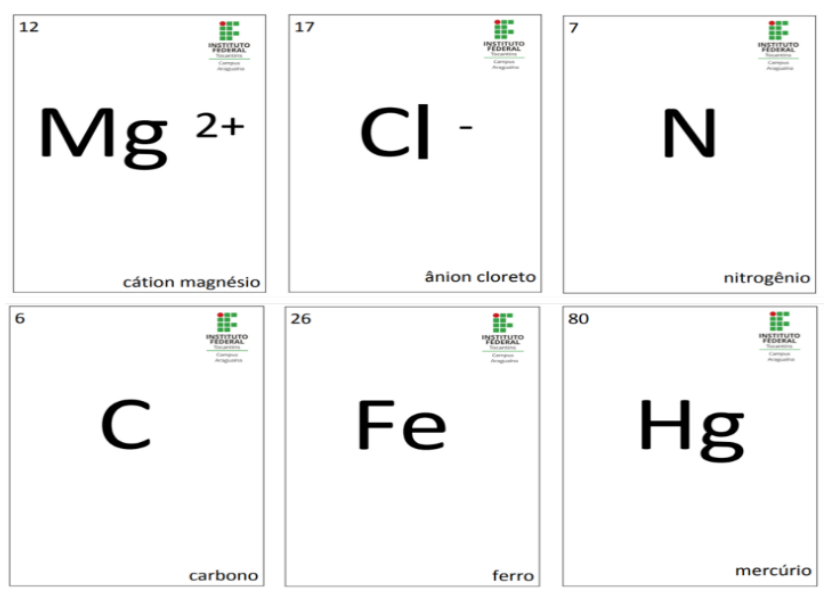

Fonte: Elaborada pelo autor, 2019.

\section{RESULTADOS E DISCUSSÃO}

No decorrer do jogo foram realizados intervenções por meio de apontamentos, indagações sobre o tipo de ligação química formada e as razões pelas quais aquele tipo de ligação proposta pela dupla (ou equipe) era ou não viável do ponto de vista teórico-conceitual.

No decorrer da aplicação do jogo foi possível perceber o empenho dos discentes na execução da atividade lúdica uma vez que, ao ouvirem o apito, buscavam inúmeras possibilidades de se organizarem aos pares na formação de um composto. Foram realizadas 5 (cinco) rodadas e em todas elas muitos estudantes conseguiram, com facilidade, formar os compostos por meio dos conhecimentos adquiridos sobre as ligações químicas. Entretanto, outros apresentaram maior dificuldade. A possibilidade de promover uma maior interação entre os próprios estudantes também foi um ponto de destaque, como nas figuras 3 e 4 . 
FIGURA 3-Alunos com as cartas em mãos.

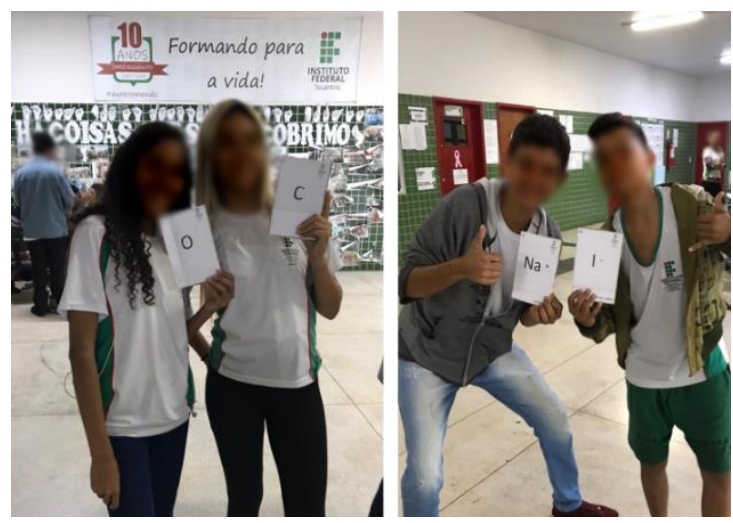

Fonte: Elaborada pelo autor, 2019.

FIGURA 4-Alunos procurando parceiros.

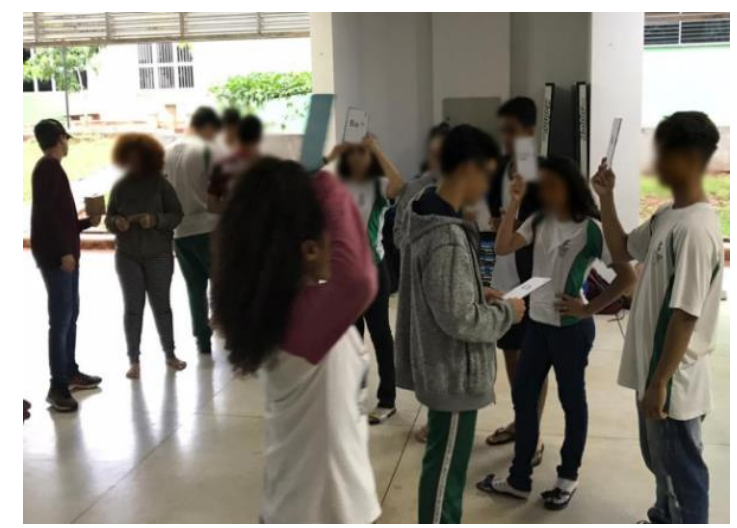

Fonte: Elaborada pelo autor, 2019.

Um dos desafios encontrados durante a aplicação do jogo foi a agitação dos estudantes ao longo da atividade lúdica. Este efeito tem uma possível explicação no fato da escolha do espaço de realização, um espaço aberto e fora do espaço de sala de aula e assim como afirmam Focetola et al. (2012), apesar de se apresentar como uma atividade lúdica o jogos educacionais não podem ser aplicados com fim de diversão para os estudantes e nem mesmo ser utilizado como única proposta de ação didática docente.

Além disso, constatamos com a primeira aplicação do jogo que se fazia necessário uma maior quantidade de cartas iguais de metais no estado elementar, além de repetir também mais algumas cartas para íons, possibilitando assim uma melhor explicação sobre a ligação metálica e uma maior variedade nas ligações covalentes.

\section{CONCLUSÃO}

O jogo didático, assim como outros dispositivos é sem dúvida uma ferramenta importante para diversificar as possibilidades de ensino e aprendizagem. Ao mesmo tempo requer muita atenção na sua aplicação e um bom planejamento na sua elaboração, tentando assim prever algumas situações possíveis de ocorrência que prejudicam a execução efetiva do jogo.

Sendo assim, o professor precisa ser ativo no papel de mediação de todo o processo, desde a elaboração até a aplicação do jogo. Deste modo, o jogo didático tem a capacidade de se apresentar como um importante recurso no processo de apropriação do conhecimento químico.

\section{AGRADECIMENTO}

Agradecemos ao apoio da CAPES, Universidade Federal do Tocantins-UFT e do Instituto Federal de Educação, Ciência e Tecnologia do Tocantins-IFTO.

Todos os autores declararam não haver qualquer potencial conflito de interesses referente a este artigo. 


\section{REFERÊNCIAS}

FOCETOLA, P.B.M.; CASTRO, P.J; SOUZA, A.C.J; GRION, L.C.; PEDRO, N.C.S.; IACK, R.S.; ALMEIDA. R.X.; OLIVEIRA, A.C.; BARROS, C.V.T.; VAISTMAN, E.; BRANDÃO, J.B; GUERRA, A.C.O.; SILVA, J.F.M. Os jogos educacionais de cartas como estratégia de ensino em química. Química Nova na Escola. v. 34, n. 4, p. 248-255, 2012.

SILVA, A. C. R.; LACERDA, P. L.; CLEOPHAS, M. G. Jogar e compreender a Química: ressignificando um jogo tradicional em didático. Amazônia - Revista de Educação em Ciências e Matemática, v.13, n. 28, p. 132-150, 2017.

ZANON, D. A. V.; GUERREIRO, M. A. S.; OLIVEIRA, R. C. Jogo didático ludo químico para o ensino de nomenclatura dos compostos orgânicos: projeto, produção, aplicação e avaliação. Ciências \& Cognição, v. 13, n. 1, p. 72-81, 2008. Disponível em: http://www.cienciasecognicao.org. 